\title{
The contribution of school meals to food consumption and nutrient intakes of young people aged 4-18 years in England
}

\author{
$M$ Nelson, K Lowes and V Hwang and members of the Nutrition Group, \\ School Meals Review Panel, Department for Education and Skills $†$ \\ Nutritional Sciences Research Division, King's College London, 150 Stamford Street, London SE 1 9NH, UK and \\ School Food Trust, N9 Moorfoot, Sheffield S1 4PQ, UK
}

Submitted 22 March 2006: Accepted 27 September 2006: First published online 6 March 2007

\begin{abstract}
Objectives: To undertake secondary analyses of the 1997 National Diet and Nutrition Survey of Young People aged 4-18 years in order to describe the contribution of school meals to daily food and nutrient intakes; and to compare the findings from 1997 with data collected in English primary and secondary schools in 2004-2005.

Design: Cross-sectional analysis of 7-day weighed inventory food consumption data according to age, sex, household income, free school meals and breakfast consumption. Comparison of food consumption with the Balance of Good Health and of nutrient intake data with the Caroline Walker Trust (CWT) guidelines.

Setting: United Kingdom.

Subjects: One thousand four hundred and fifty-six UK schoolchildren aged 4-18 years, 7058 English primary-school pupils and 5695 English secondary-school pupils. Results: Pupils' school meal choices in 1997 did not accord with the Balance of Good Health. Food choices in school were less healthy than choices outside school. School meals failed to make good the shortfalls in daily intakes of non-starch polysaccharides and zinc in primary-school pupils, and of calcium, iron, zinc, vitamin A and nonstarch polysaccharides in secondary-school pupils, nor excess daily intakes of saturated fatty acids, non-milk extrinsic sugars and sodium at all ages. School meals typically failed to meet CWT guidelines. They were more likely to meet CWT guidelines when choice of foods was restricted.

Conclusions: School meals need substantial improvement to meet CWT guidelines for healthy eating. The introduction of food-based guidelines for school meals in England in 2001 did not improve the food choices in school meals.
\end{abstract}

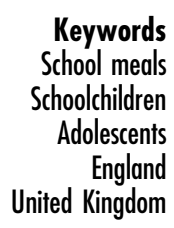

Every school day in England roughly three million school meals are served. They make a vital contribution to the dietary intake of schoolchildren in England. The National Diet and Nutrition Survey (NDNS) of children aged 4-18 years ${ }^{1}$ showed that in 1997 typically one-quarter to onethird of the daily intake of energy, fat, fibre, iron, calcium, vitamin $\mathrm{C}$ and folate came from the meal the child obtained at school. These contributions were greater in those receiving free school meals and those who did not eat breakfast. It is important, therefore, that school meals constitute a balanced meal containing sufficient nutrients to help ensure that requirements for energy, macro- and micronutrients are met in schoolchildren.

From 1941 until 1979, the Government had stipulated a legal requirement for schools to provide meals that met designated nutritional standards. In 1980, this requirement was removed. Thereafter, schools were free to introduce a

†Panel members: J Buttriss, H Crawley, M Nelson, M Rayner, L Stockley and C Weir. wide range of foods and (primarily in secondary schools) cafeteria-style service. Children were therefore able to exercise choice over what they had at lunchtime, but there was little control over what they consumed. Increasingly, the foods on offer tended to cater for children's liking of fatty fried foods (e.g. chips and burgers) and soft drinks.

In 1992, the Caroline Walker Trust (CWT) published guidelines for school meals ${ }^{2}$. They were introduced to provide schools and caterers with a nutritional framework for providing healthy foods at school. They gave recommended nutrient contents of an average school meal for children over a period of one week, expressed in terms of Dietary Reference Values (DRV) for food energy and nutrients for the $\mathrm{UK}^{3}$. The CWT guidelines arose from concerns about the balance of foods on offer to and being consumed by children at school. The CWT guidelines had no legal standing, but they provided an unofficial benchmark for those schools seeking to improve school meals.

Following growing concerns about the nutritional content of school lunches and the increasing levels of 
childhood obesity in England ${ }^{4}$, in April 2001 the Department for Education and Skills (DfES) introduced new compulsory National Nutritional Standards ${ }^{5}$. These standards were food-based and set out to ensure that children had the opportunity at lunchtime to select healthy balanced meals. Caterers in secondary schools were required to ensure that at least two items from each of the following food groups were on offer at lunchtime:

- Starchy foods (rice, pasta, bread, potatoes) - at least one not cooked in oil.

- One portion of fruit.

- One portion of vegetables (not including potatoes).

- Fish at least two times a week.

- Red meat at least three times a week (and suitable alternatives for vegetarians).

In addition, although not compulsory, caterers were encouraged to provide:

- Free drinking water.

- Drinking milk.

- Hot food, especially during the cold months.

Similar standards and recommendations were given for primary schools, except that starchy foods cooked in oil were not to be served more than three times per week, fruit-based desserts* were to be served at least twice per week, meat was to be served at least twice rather than three times per week, and fish was to be served at least once rather than twice per week. All food provision was recommended to accord with the Balance of Good Health, a plate model showing the relative recommended contributions of different food groups to a healthy diet.

In 2004, a survey was carried out on school meals in a nationally representative sample of 79 secondary schools in England, with the choices of 5695 pupils being reported ${ }^{6}$. The survey reported on what was on offer at schools, catering practices, contract arrangements and school food policies, and pupils' consumption of foods provided by the schools at lunchtime. The findings showed that while most schools were meeting the 2001 DfES guidelines regarding provision (at least at the beginning of the lunch period), children's choices were nutritionally poor. The majority of choices were for high-fat foods, chips and potatoes cooked in fat, and soft drinks. Pupils' choices consistently failed to meet most of the CWT guidelines. A parallel study of over 7000 primary pupils' consumption carried out in 2005 revealed similar findings ${ }^{7}$, in spite of the narrower range of choice in primary-school dining rooms compared with the cash cafeterias in secondary schools. Thus, the 2001 standards for school meals seemed to have had little beneficial effect on pupils' choices.

In response to the growing evidence that school meals were failing to meet healthy eating guidelines, the DfES

*The composition of fruit-based desserts was not defined. established the School Meals Review Panel (SMRP) to revise the guidelines for school meals ${ }^{8}$. The SMRP recognised that school lunches play an important role in the diets of schoolchildren, and that school lunches are an important focus for public health initiatives because of the implications for the health and performance of children in both the short and long term. The remit of the SMRP was, inter alia, to recommend what form nutritional standards for schools should take in the future; and in making this recommendation, to strongly consider the introduction of nutrientbased nutritional standards in schools, using the CWT guidelines as a starting point. The CWT guidelines were revised in $2005^{\circ}$, and the SMRP had access to the revised guidelines prior to their publication in September 2005.

The surveys of primary and secondary school meals conducted in 2004-2005 were valuable for two reasons. First, they provided objective evidence of children's choices at lunchtime (rather than children's reported consumption based on food inventories used in the 1997 NDNS). Second, they provided evidence of the context (catering provision, dining environment, healthy eating initiatives, etc.) within which to assess the influence of factors potentially associated with healthier choices by the children. They were limited, however, by the absence of information about foods eaten at other times of the day. Thus, the 1997 NDNS, although not providing information on school catering practices or the dining environment, did report on food choices at school and throughout the day of over 1400 children in primary and secondary schools in the UK.

The aim of the present paper is threefold: (1) to describe the contribution of school meals to total consumption in 1997; (2) to compare school lunch choices in 1997 with those in 2004/2005 to assess if, at a population level, there are any changes which could reasonably be attributed to the 2001 DfES guidelines for school meals; and (3) to see if the recommendations currently being proposed by the SMRP regarding the nutrient content of school meals (expressed in terms of DRV) are reasonable in terms of the contribution that school meals make currently and potentially in the future to total intake.

\section{Methods}

The 1997 NDNS data collected dietary information from 1701 males and females aged 4-18 years. These data were used to determine the contribution of school lunches to daily total energy and nutrient intakes.

Information was collected on the health of the child, and each respondent was categorised into one of three groups:

1. Not unwell.

2. Unwell eating not affected.

3. Unwell with eating affected.

Those who stated they were unwell with eating affected were excluded from the data analysed. A further exclusion 
variable was dieting to lose weight, on the grounds they would not be making food choices consistent with normal growth and energy balance. Two hundred and forty-five respondents were thus excluded from the original sample, leaving a total of 1456 school pupils across the UK, 743 in primary school and 713 in secondary school.

The CWT guidelines recommend the contributions that school lunches should make to total daily intake for 12 nutrients (energy, protein, fat, carbohydrate, non-starch polysaccharides (NSP), calcium, iron, zinc, vitamin A, vitamin $\mathrm{C}$, folate and sodium). This provided the list of nutrients analysed for the present paper. The recommendations are expressed in terms of both absolute amounts and as a percentage of the Reference Nutrient Intake $(\mathrm{RNI})^{3}$.

In order to determine the contribution of school meals to the children's overall diet, the data were filtered to identify categories according to the type of midday meal eaten:

1. School meal days.

2. Packed lunch day.

3. Other days.

The contribution of the midday meal on school lunch days was then determined for foods and nutrients. This allowed comparison with the CWT guidelines and the Balance of Good Health recommendations ${ }^{10}$. The present analysis also compared the quantities of food consumed at lunchtime on school meal days in the NDNS and the 2004 and 2005 surveys of school meals.

\section{Free school meals, income and food choice}

Free school meals were available to those children whose parents received Income Support or income-based Jobseekers Allowance. Those in receipt of Family Credit were not eligible for free school meals but were identified for purposes of comparison with those who were eligible. Uptake of eligibility to free school meals was determined by dividing the number of pupils reporting having received free school meals by the number deemed eligible based on their families' sources of income.

Pupils were divided according to weekly gross household income in $£ 40$ bands ( $£ 40$ or less, $£ 40$ but less than $£ 80$, 80 but less than $£ 120$, etc.). In bands with gross income of less than $£ 240$ per week, $31 \%$ or more of pupils were receiving free school meals. At $\$ 240$ or more, $8 \%$ or less of pupils received free school meals. $£ 240$ was therefore used as the boundary demarcating low income.

\section{Role of the 2001 DfES National Nutritional Standards for school meals}

The 1997 data on food choices were compared with the $2004 / 2005$ food choice data from primary- and secondaryschool pupils 6,7 in order to assess whether or not the guidelines set in 2001 have made a difference to school meals and their potential contribution to children's nutritional status.

\section{Results}

Food choices and nutrient intakes in 1997

Table 1 shows the mean intakes of energy and nutrients for 1456 pupils attending primary and secondary schools the UK in 1997. Mean intakes of energy, zinc and NSP were below the DRV (Estimated Average Requirement (EAR) for energy and RNI for nutrients) in both primary- and secondary-school children of both sexes. Average intakes of sodium were well in excess of the RNI in all groups. Boys and girls in secondary schools had mean calcium intakes at $85 \%$ of the RNI, and girls in secondary schools had mean iron and vitamin A intakes below the RNI. The percentage contributions of saturated fatty acids and nonmilk extrinsic sugars (NMES) to total energy intake were well above the $11 \%$ recommended.

Figure 1 shows the Balance of Good Health model, which defines the proportion of foods that should be provided by five different food groups ${ }^{5}$. Figure 2 shows how the percentage of food items chosen by pupils at school lunchtimes compared with the Balance of Good Health recommendations. Foods and drinks containing high levels of fat or sugar were the most commonly chosen food group ( $41 \%$ of the food choices in primaryand $48 \%$ in secondary-school lunches vs. $8 \%$ recommended in the Balance of Good Health). Within this group, the main contributors were desserts and cakes (35\%), fizzy drinks (31\%) and chips and other potatoes cooked with oil or fat (27\%). In contrast, the proportions of choices from the group comprising bread, other cereals and potatoes not cooked with oil or fat, and the fruit and vegetables group (18\% of which were baked beans) were both substantially below the Balance of Good Health recommendations (both of which are 33\% of the diet). Within the meat, fish and alternatives group, sausages constituted $20 \%$ of foods chosen. Selection of milk and dairy products was one-third (in secondaryschool pupils) to just over one-half (in primary-school pupils) of the recommended amount (15\%), within which $39 \%$ was represented by whole milk and $25 \%$ by cheese.

Table 2 shows the food choices of both primary- and secondary-school children as a percentage of all items chosen, from all sources, at school and outside school. The main food choices amongst primary-school children overall (total daily intake), accounting for 55\% of all food choices, were soft drinks, pasta, rice, bread and other cereals, milk and milk products, sugar, preserves and confectionery, and desserts etc. Differences between boys and girls were minor. When foods eaten at school were compared with foods eaten outside school, primary-school children were more likely to have vegetables ( $9 \%$ vs. 4-6\%), potatoes (both 'not fried' 
Table 1 Mean daily energy and nutrient intakes of 1456 primary- and secondary-school children in the United Kingdom, 1997, and intake expressed in terms of Dietary Reference Values (DRV)

\begin{tabular}{|c|c|c|c|c|c|c|c|c|}
\hline & \multicolumn{4}{|c|}{ Primary } & \multicolumn{4}{|c|}{ Secondary } \\
\hline & \multicolumn{2}{|c|}{ Male $(n=390)$} & \multicolumn{2}{|c|}{ Female $(n=353)$} & \multicolumn{2}{|c|}{ Male $(n=360)$} & \multicolumn{2}{|c|}{ Female $(n=353)$} \\
\hline & Mean & SD & Mean & SD & Mean & SD & Mean & SD \\
\hline \multicolumn{9}{|l|}{ Mean daily intake } \\
\hline Energy (kcal) & 1694 & 496 & 1536 & 435 & 2157 & 750 & 1696 & 576 \\
\hline Energy (kJ) & 7121 & 2080 & 6456 & 1825 & 9066 & 3145 & 7127 & 2415 \\
\hline Protein $(\mathrm{g})$ & 53.6 & 19.1 & 49.2 & 16.7 & 70.9 & 27.9 & 55.7 & 22.3 \\
\hline Fat $(\mathrm{g})$ & 66.8 & 25.7 & 61.2 & 22.7 & 84.7 & 36.6 & 68.0 & 29.3 \\
\hline SFA $(g)$ & 27.5 & 11.3 & 25.3 & 10.1 & 33.0 & 15.6 & 26.5 & 12.7 \\
\hline MUFA (g) & 21.8 & 9.3 & 19.8 & 8.0 & 28.2 & 13.0 & 22.4 & 10.5 \\
\hline PUFA (g) & 10.6 & 5.7 & 9.7 & 5.3 & 14.7 & 8.3 & 12.0 & 7.0 \\
\hline $\mathrm{CHO}(\mathrm{g})$ & 234 & 71 & 210 & 64 & 290 & 107 & 227 & 84 \\
\hline $\operatorname{NSP}(\mathrm{g})$ & 9.9 & 4.4 & 9.2 & 4.2 & 12.6 & 6.0 & 10.5 & 5.2 \\
\hline Sodium (mg) & 2305 & 916 & 2052 & 810 & 3008 & 1363 & 2335 & 1017 \\
\hline Calcium (mg) & 747 & 339 & 672 & 301 & 850 & 434 & 679 & 369 \\
\hline Iron (mg) & 9.2 & 3.8 & 8.2 & 3.5 & 11.8 & 5.5 & 9.1 & 5.0 \\
\hline Zinc (mg) & 6.0 & 2.6 & 5.5 & 2.2 & 8.0 & 3.9 & 6.2 & 3.1 \\
\hline Vitamin A $(\mu \mathrm{g})$ & 332 & 455 & 307 & 605 & 360 & 1075 & 306 & 1048 \\
\hline Vitamin C (mg) & 76 & 69 & 77 & 60 & 85 & 84 & 81 & 90 \\
\hline Folate $(\mu \mathrm{g})$ & 207 & 91 & 186 & 81 & 279 & 155 & 216 & 121 \\
\hline \multicolumn{9}{|c|}{ Percentage of energy intake } \\
\hline Fat (\% energy) & 35 & 7 & 35 & 7 & 35 & 8 & 36 & 8 \\
\hline SFA (\% energy) & 14 & 4 & 15 & 4 & 14 & 4 & 14 & 4 \\
\hline $\mathrm{CHO}$ (\% energy) & 52 & 7 & 51 & 7 & 51 & 8 & 50 & 9 \\
\hline NMES (\% energy) & 17 & 8 & 17 & 8 & 16 & 8 & 16 & 9 \\
\hline \multicolumn{9}{|l|}{ Percentage of DRV } \\
\hline Energy (kcal) & 91 & 26 & 93 & 26 & 88 & 30 & 87 & 30 \\
\hline Protein & 222 & 86 & 204 & 73 & 149 & 57 & 130 & 52 \\
\hline Sodium & 245 & 109 & 219 & 98 & 188 & 85 & 146 & 64 \\
\hline Calcium & 149 & 70 & 134 & 62 & 85 & 43 & 85 & 46 \\
\hline Iron & 124 & 52 & 111 & 47 & 104 & 49 & 61 & 34 \\
\hline Zinc & 89 & 38 & 81 & 32 & 87 & 41 & 78 & 41 \\
\hline Vitamin A & 110 & 111 & 104 & 136 & 97 & 186 & 92 & 187 \\
\hline Vitamin C & 252 & 229 & 256 & 202 & 229 & 226 & 217 & 238 \\
\hline Folate & 165 & 78 & 149 & 69 & 140 & 77 & 108 & 61 \\
\hline NSP & 75 & 33 & 60 & 27 & 73 & 35 & 58 & 29 \\
\hline
\end{tabular}

SD - standard deviation; SFA - saturated fatty acids; MUFA - monounsaturated fatty acids; PUFA - polyunsaturated fatty acids; $\mathrm{CHO}$ - carbohydrates; NSP - non-starch polysaccharides; NMES - non-milk extrinsic sugars.

(5-6\% vs. $2 \%)$ and 'chips and other fried' (6\% vs. $2 \%)$ ), higher-fat main dishes $(8-10 \%$ vs. $3 \%)$, desserts etc. $(16-18 \%$ vs. $6-7 \%)$ and water $(6-7 \%$ vs. $2-3 \%)$. They were less likely to have pasta, rice, bread and other

\section{The Balance of Good Health}

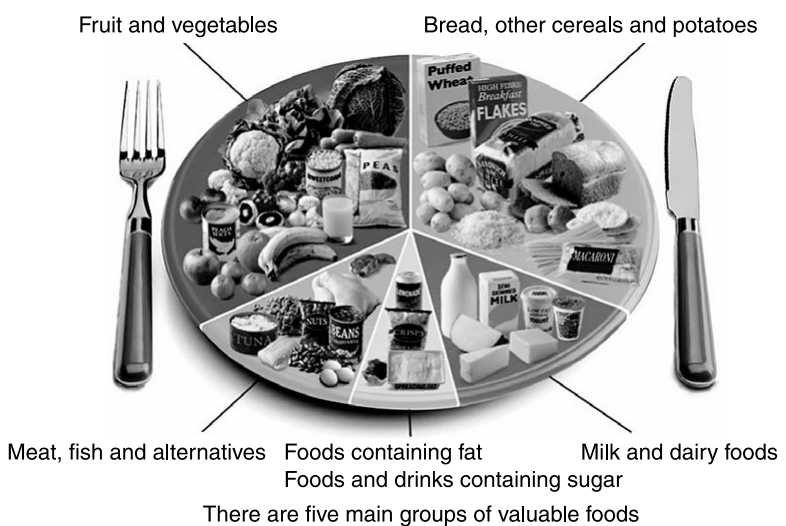

Fig. 1 The Balance of Good Health model (reproduced by kind permission of the Food Standards Agency) cereals (6\% vs. $13-14 \%)$, milk and milk products (7-8\% vs. $14 \%$ ), sugar, preserves and confectionery (3\% vs. $10 \%)$ and soft drinks (10-13\% vs. $15 \%)$. Thus, primaryschool children were up to three times as likely to have

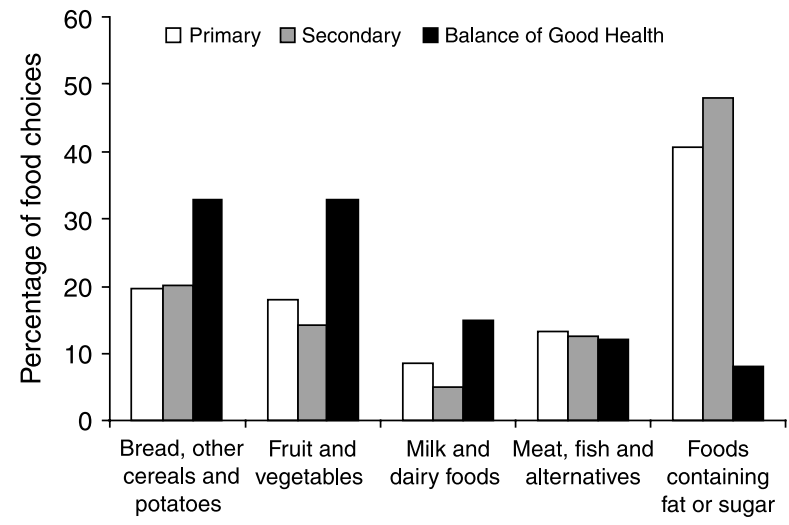

Fig. 2 Percentage of food choices amongst 1456 British primaryand secondary-school pupils at school lunchtimes compared with the Balance of Good Health recommendations 
Table 2 Food choices as a percentage of all items eaten (all sources, at school, outside school) of 1456 primary- and secondary-school children in the United Kingdom, 1997, by sex and age

\begin{tabular}{|c|c|c|c|c|c|}
\hline & \multicolumn{2}{|c|}{ Primary } & \multicolumn{2}{|c|}{ Secondary } & \multirow[b]{2}{*}{ Tota } \\
\hline & $\begin{array}{c}\text { Male } \\
(n=390)\end{array}$ & $\begin{array}{c}\text { Female } \\
(n=353)\end{array}$ & $\begin{array}{c}\text { Male } \\
(n=360)\end{array}$ & $\begin{array}{c}\text { Female } \\
(n=353)\end{array}$ & \\
\hline \multicolumn{6}{|l|}{ Total daily intake } \\
\hline Soft drinks & 13.4 & 14.5 & 13.4 & 11.4 & 13.2 \\
\hline Pasta, rice, bread, other cereals & 11.6 & 10.9 & 12.1 & 11.5 & 11.5 \\
\hline Milk and milk products & 12.2 & 12.4 & 10.6 & 10.1 & 11.4 \\
\hline Sugar, preserves, confectionery & 7.5 & 8.0 & 10.0 & 10.0 & 8.8 \\
\hline Desserts, puddings, cakes, biscuits, ice cream & 10.4 & 9.5 & 7.0 & 6.9 & 8.5 \\
\hline Sandwiches and other foods & 5.6 & 5.3 & 8.4 & 9.2 & 7.1 \\
\hline Vegetables & 5.9 & 7.0 & 5.9 & 7.6 & 6.6 \\
\hline Higher-fat main dishes and ingredients & 5.5 & 4.8 & 5.8 & 4.6 & 5.2 \\
\hline Lower-fat main dishes and ingredients & 3.4 & 3.8 & 4.4 & 4.5 & 4.0 \\
\hline Butter, margarine, oil & 3.9 & 3.6 & 4.3 & 4.3 & 4.0 \\
\hline Chips and other fried potatoes & 3.3 & 3.3 & 4.7 & 3.6 & 3.7 \\
\hline Water & 4.1 & 3.5 & 2.9 & 3.4 & 3.5 \\
\hline Savoury snacks, nuts, seeds & 2.5 & 2.8 & 3.3 & 4.1 & 3.2 \\
\hline Fruit & 3.5 & 3.7 & 1.9 & 2.7 & 3.0 \\
\hline Potatoes not fried & 3.5 & 3.1 & 1.9 & 2.3 & 2.7 \\
\hline Fruit juice & 1.4 & 1.7 & 1.6 & 1.8 & 1.6 \\
\hline Baked beans & 1.7 & 1.4 & 1.5 & 1.2 & 1.5 \\
\hline Eggs and egg dishes & 0.6 & 0.7 & 0.5 & 0.7 & 0.6 \\
\hline \multicolumn{6}{|l|}{ Intake at school } \\
\hline Desserts, puddings, cakes, biscuits, ice cream & 18.0 & 16.4 & 10.7 & 8.8 & 13.7 \\
\hline Soft drinks & 10.1 & 12.8 & 15.7 & 12.5 & 12.6 \\
\hline Higher-fat main dishes and ingredients & 9.7 & 8.5 & 11.4 & 7.8 & 9.2 \\
\hline Vegetables & 9.4 & 9.3 & 6.7 & 8.7 & 8.6 \\
\hline Pasta, rice, bread, other cereals & 6.0 & 5.7 & 8.3 & 8.4 & 7.0 \\
\hline Chips and other fried potatoes & 5.9 & 5.7 & 9.6 & 6.4 & 6.7 \\
\hline Milk and milk products & 7.4 & 8.1 & 3.9 & 4.9 & 6.2 \\
\hline Sugar, preserves, confectionery & 2.9 & 3.1 & 7.4 & 9.4 & 5.5 \\
\hline Water & 7.4 & 6.2 & 2.8 & 3.6 & 5.1 \\
\hline Savoury snacks, nuts, seeds & 2.1 & 3.5 & 4.7 & 7.3 & 4.4 \\
\hline Potatoes not fried & 6.5 & 5.3 & 2.1 & 2.4 & 4.3 \\
\hline Sandwiches and other foods & 2.5 & 2.7 & 4.5 & 5.9 & 3.8 \\
\hline Lower-fat main dishes and ingredients & 3.5 & 3.4 & 3.4 & 3.8 & 3.5 \\
\hline Fruit & 3.1 & 4.0 & 0.9 & 2.7 & 2.8 \\
\hline Butter, margarine, oil & 1.7 & 1.7 & 4.1 & 4.1 & 2.8 \\
\hline Baked beans & 3.0 & 2.3 & 2.8 & 2.0 & 2.5 \\
\hline Fruit juice & 0.4 & 0.8 & 0.9 & 1.0 & 0.8 \\
\hline Eggs and egg dishes & 0.4 & 0.5 & 0.3 & 0.4 & 0.4 \\
\hline \multicolumn{6}{|l|}{ Intake outside school } \\
\hline Milk and milk products & 14.5 & 14.5 & 13.3 & 12.5 & 13.7 \\
\hline Pasta, rice, bread, other cereals & 14.3 & 13.3 & 13.6 & 12.9 & 13.5 \\
\hline Soft drinks & 14.9 & 15.3 & 12.4 & 10.9 & 13.4 \\
\hline Sugar, preserves, confectionery & 9.7 & 10.3 & 11.0 & 10.2 & 10.3 \\
\hline Sandwiches and other foods & 7.0 & 6.6 & 9.9 & 10.8 & 8.5 \\
\hline Desserts, puddings, cakes, biscuits, ice cream & 6.9 & 6.3 & 5.5 & 6.0 & 6.2 \\
\hline Vegetables & 4.3 & 5.9 & 5.6 & 7.1 & 5.7 \\
\hline Butter, margarine, oil & 4.9 & 4.5 & 4.4 & 4.4 & 4.6 \\
\hline Lower-fat main dishes and ingredients & 3.3 & 3.9 & 4.7 & 4.9 & 4.2 \\
\hline Higher-fat main dishes and ingredients & 3.5 & 3.1 & 3.6 & 3.2 & 3.4 \\
\hline Fruit & 3.7 & 3.5 & 2.3 & 2.8 & 3.1 \\
\hline Water & 2.6 & 2.3 & 2.9 & 3.3 & 2.8 \\
\hline Savoury snacks, nuts, seeds & 2.7 & 2.5 & 2.7 & 2.6 & 2.6 \\
\hline Chips and other fried potatoes & 2.1 & 2.1 & 2.8 & 2.3 & 2.3 \\
\hline Fruit juice & 1.9 & 2.1 & 1.9 & 2.2 & 2.0 \\
\hline Potatoes not fried & 2.0 & 2.0 & 1.8 & 2.2 & 2.0 \\
\hline Baked beans & 1.0 & 1.0 & 1.0 & 0.9 & 1.0 \\
\hline Eggs and egg dishes & 0.7 & 0.7 & 0.6 & 0.9 & 0.7 \\
\hline
\end{tabular}

higher-fat foods (e.g. main dishes and chips) and higherfat and sugar foods (e.g. desserts etc.) at school than outside school. They were also more likely to have vegetables and water at school.
The main food choices amongst secondary-school children overall (total daily intake), accounting for over half of all food choices, were the same as amongst primaryschool children. Secondary-school children chose more 
sugar, preserves and confectionery and fewer milk and milk products, and desserts etc. Again, differences between boys and girls were minor. Comparing foods eaten in school with those eaten outside school, secondary-school children were more likely to have vegetables (7-9\% vs. 6$7 \%$ ), chips and other fried potatoes (6-10\% vs. 2-3\%), savoury snacks (5-7\% vs. 3\%), higher-fat main dishes (8-11\% vs. 3-4\%) and desserts etc. (9-11\% vs. 6\%). They were less likely to have pasta, rice, bread and other cereals ( $8 \%$ vs. $13-14 \%$ ), milk and milk products (4-5\% vs. $12-$ $13 \%)$, and sugar, preserves and confectionery (7-9\% vs. 10-11\%). Thus, like primary-school children, secondaryschool children were up to three times more likely to have higher-fat foods (e.g. main dishes and chips) at school than outside school. They were twice as likely to have higher-fat and sugar foods (e.g. savoury snacks, desserts etc.) at school than outside school, and much less likely to have milk and milk products and lower-fat cereal foods (e.g. pasta, bread, rice).

Figures 3 and 4 show the mean percentage of the DRV provided by school meals and the 2005 CWT recommendations in primary and secondary schools, respectively. The error bars show standard errors. For energy and all nutrients except sodium, the recommendations are minima; for sodium (indicated by the shaded bars) the recommendation for intake is a maximum. In primary schools (Fig. 3), meals provided substantially less than the recommended values for NSP (30\% of DRV) and for iron, zinc and vitamin A (40\% of DRV). Intakes of sodium were over twice the recommended amount (30\%). There were few important differences between boys and girls except for lower NSP intakes in girls as a percentage of DRV. In secondary schools (Fig. 4), intakes were well below the recommendations for NSP, calcium, iron, zinc, vitamin A and folate. Girls had substantially lower NSP and iron intakes as a percentage of DRV compared with boys, but higher intakes of calcium.

\section{Free school meals and low income}

A free school meal was available to those children whose parents received Income Support or income-based Jobseekers Allowance (Table 3). Between 11\% and 19\% of children lived in families in receipt of Income Support or Jobseekers Allowance, and a further 11-20\% lived in families in receipt of Family Credit. Between 23\% (secondary girls) and $72 \%$ (primary boys) took up their eligibility for free school meals. Children living in households in receipt of Family Credit were technically not eligible for free school meals, but between 3 and 14\% reported that their children received free school meals, substantially higher in boys than in girls. Some possible reasons for the apparent discrepancies are given in the Discussion.

In both primary and secondary schools, pupils who received free school meals had lower mean percentage RNI values for calcium and vitamin C compared with those who did not have free school meals; and in secondary schools a lower percentage RNI for folate also. However, pupils in receipt of free school meals derived a significantly greater proportion of their daily energy and nutrient intakes from their school meals than those who did not have a free school meal (Table 4) $(P<0.001$ for energy and all nutrients in primary schools; $P<0.01$ for energy and all nutrients in secondary schools except for vitamin A, $P>0.05)$. Because of the close association between free school meals eligibility and income, similar findings were observed in relation to differences in the adequacy of the diet in relation to family income above or below 240 per week (data not shown). Analysis according to type of income (Income Support and Jobseekers Allowance, Family Credit, or not in receipt of benefits) showed that the contribution of school meals to total intake was typically greatest for pupils in families in receipt of Income Support or Jobseekers Allowance, intermediate for pupils living in families in receipt of Family Credit, and least for pupils in families not in receipt of benefits (Fig. 5).

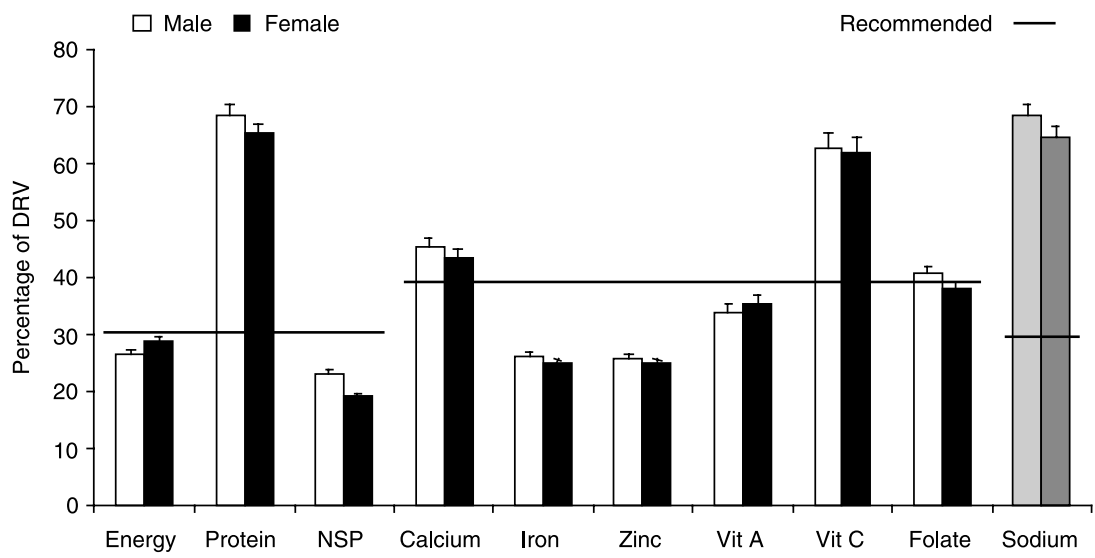

Fig. 3 Percentage of Dietary Reference Values (DRV) from school lunches eaten by 643 UK primary-school pupils in 1997, compared with 2005 Caroline Walker Trust recommendations ${ }^{9}$. Error bars show standard errors (NSP - non-starch polysaccharides) 


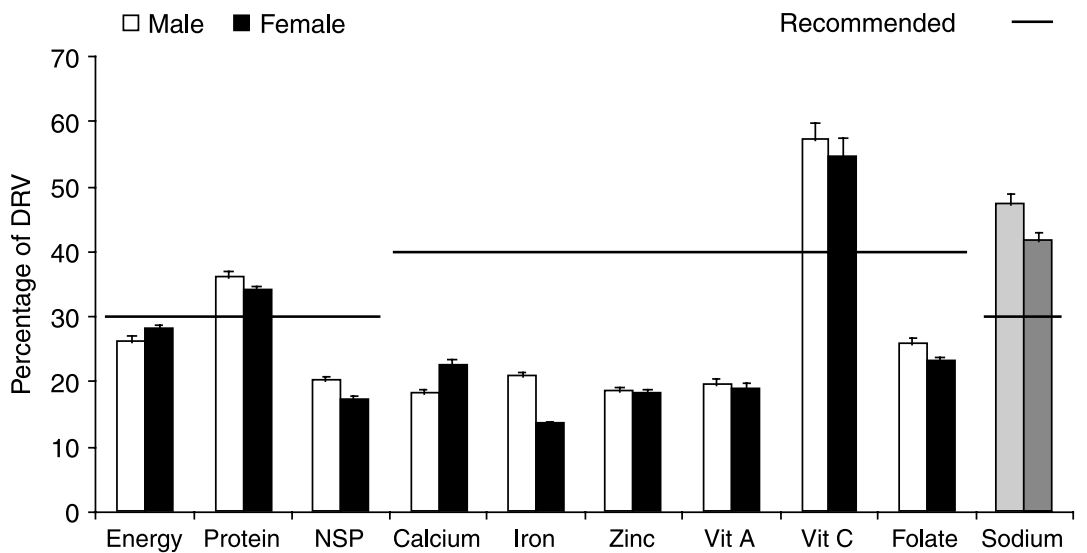

Fig. 4 Percentage of Dietary Reference Values (DRV) from school lunches eaten by 713 UK secondary-school pupils in 1997, compared with 2005 Caroline Walker Trust recommendations ${ }^{9}$. Error bars show standard errors (NSP - non-starch polysaccharides)

\section{Breakfast eating and school meals}

Sixty-two per cent of pupils reported having breakfast with cereal, 29\% had breakfast without cereal, and overall 9\% had no breakfast. The percentage not reporting breakfast was lowest in primary-school boys (4\%) and girls (5\%) and highest in secondary-school boys (9\%) and girls (25\%). Nutrient intakes of pupils who did not have breakfast were significantly lower than of those who did have breakfast (whether or not cereal was included). In addition, their school meals had lower energy and nutrient contents than meals chosen by pupils who had breakfast. However, the contribution to daily nutrient intakes from school meals was highest in those who had not had breakfast, intermediate in those who had breakfast without cereal, and lowest in those who had breakfast with cereal (Fig. 6).

\section{School meal food choices in 1997, 2004 and 2005}

The distribution of food choices in school meals reported in 1997 is compared with those observed in primaryschool pupils in 2005 and secondary-school pupils in 2004

Table 3 Percentage of 1456 primary- and secondary-school children in the United Kingdom, 1997, eligible for and reporting uptake of free school meals, according to source of benefit

\begin{tabular}{|c|c|c|c|c|}
\hline & \multicolumn{2}{|c|}{ Primary } & \multicolumn{2}{|c|}{ Secondary } \\
\hline & $\begin{array}{c}\text { Male } \\
(n=390)\end{array}$ & $\begin{array}{c}\text { Female } \\
(n=353)\end{array}$ & $\begin{array}{c}\text { Male } \\
(n=360)\end{array}$ & $\begin{array}{l}\text { Female } \\
(n=353\end{array}$ \\
\hline \multicolumn{5}{|l|}{ Eligible (\%) } \\
\hline Income Support & 14 & 16 & 10 & 12 \\
\hline Jobseekers Allowance & 1 & 3 & 1 & 3 \\
\hline Family Credit & 11 & 10 & 19 & 20 \\
\hline Any benefit ${ }^{\star}$ & 25 & 27 & 19 & 20 \\
\hline \multicolumn{5}{|l|}{ Uptake (\%) } \\
\hline Income Support & 72 & 69 & 65 & 52 \\
\hline Jobseekers Allowance & 50 & 58 & 50 & 23 \\
\hline Family Credit & 14 & 3 & 12 & 3 \\
\hline Any benefit* & 44 & 43 & 42 & 33 \\
\hline
\end{tabular}

* Values for percentage receiving benefit or taking up entitlement to free schools meals are not additive.
(Fig. $7 \mathrm{a}$ and $7 \mathrm{~b}$, respectively). The order of the food groups accords with the preferences shown in the 2004 and 2005 surveys. In primary schools in 1997, pupils reported lower consumption of vegetables and salads, chips and potatoes cooked with fat, and pasta and other cereals than was observed directly in 2005. The pupils also reported higher consumption of soft drinks, milk and milk products, and butter, margarine, sugar, preserves and confectionery and snacks than was observed directly. In secondary schools, pupils reported lower consumption of higher-fat main dishes, chips and other potatoes cooked with fat, pasta and other cereals than was observed

Table 4 Percentage contribution of school meals to total daily energy and nutrient intakes of 1456 primary- and secondaryschool pupils in England, according to whether or not pupil was in receipt of a free school meal, by age*

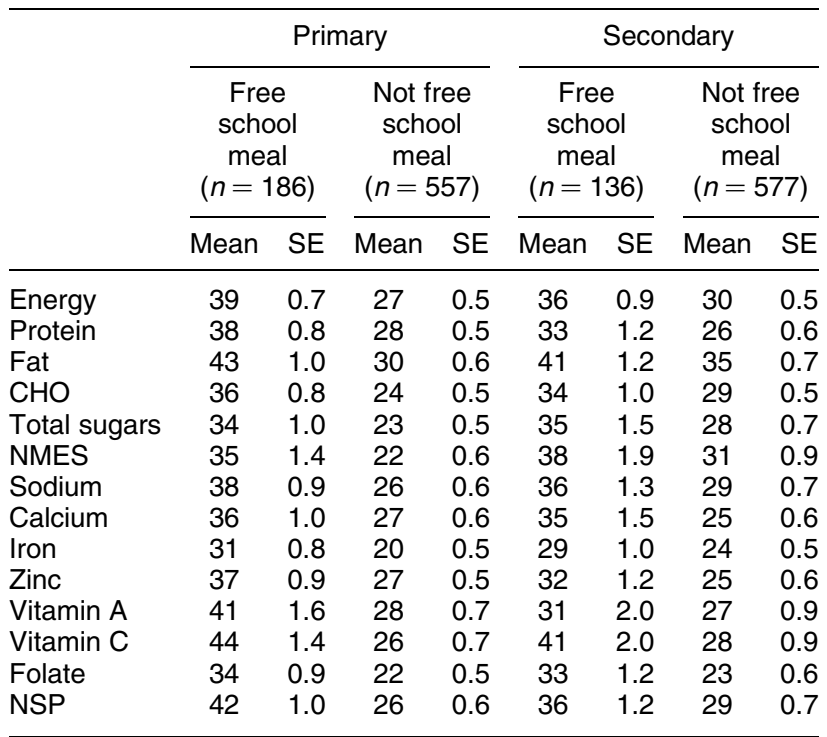

SE - standard error; CHO - carbohydrates; NMES - non-milk extrinsic sugars; NSP - non-starch polysaccharides.

${ }^{*}$ Free school meals versus not free school meals: $P<0.001$ for energy and all nutrients in primary schools, $P<0.01$ for energy and all nutrients in secondary schools except for vitamin A, $P>0.05$. 


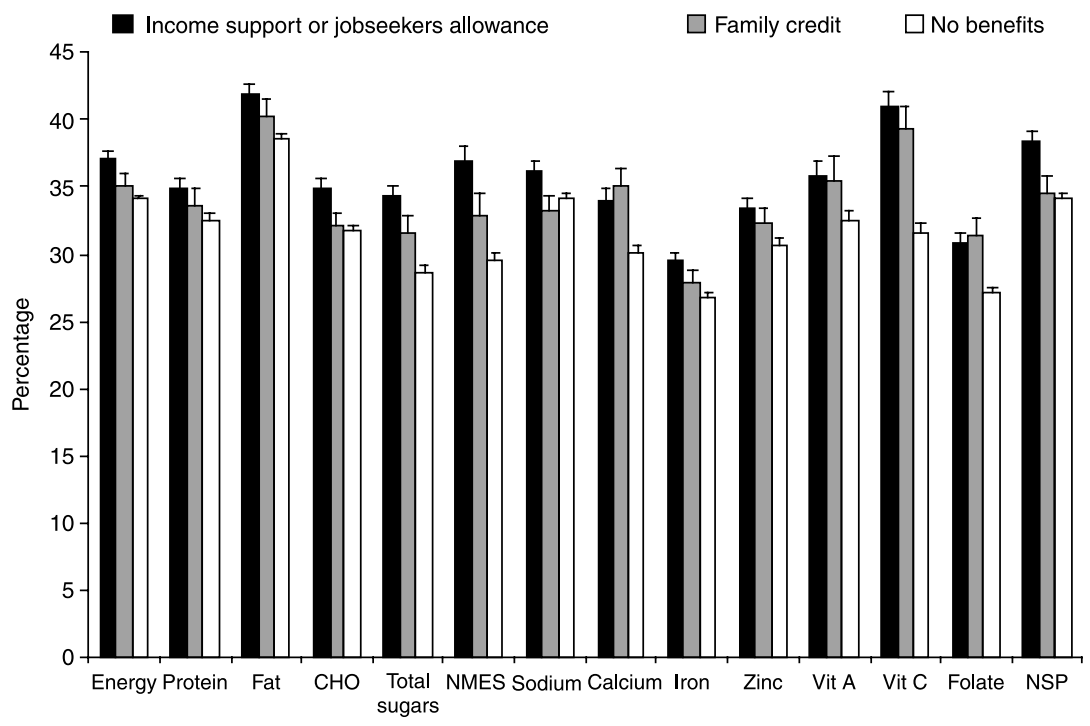

Fig. 5 Percentage contribution of school meals to total daily energy and nutrient intakes, according to whether or not pupil lived in a family in a receipt Income Support or Jobseekers Allowance, Family Credit, or neither. Error bars show standard errors (CHO - carbohydrates; NMES - non-milk extrinsic sugars; NSP - non-starch polysaccharides)

directly in 2004, and reported higher consumption of vegetables and salads, sugar, preserves and confectionery, and savoury snacks than was observed.

These differences may have occurred for several reasons. First, there may have been a real shift in the choices made by pupils. Second, there were methodological differences between the 1997 survey (based on consumption reported by children and parents) and the 2004 and 2005 findings (based on direct observations of pupils food choices in the dining room). Third, in relation to primary schools, catering staff would have been aware of the presence of observers in the dining room and may have chosen to serve foods such as vegetables and salads more often and soft drinks less often (although this does not accord with lower levels of milk and milk products being observed than reported in 1997). Such an influence would have been much less marked in secondary schools in 2005, where pupils have much more freedom of choice.

\section{Discussion}

The NDNS of young people aged 4-18 years ${ }^{5}$ conducted in 1997 showed that the average diet of UK children was not well balanced (Table 1). The diets were high in saturated fat, NMES and sodium, low in zinc and NSP in

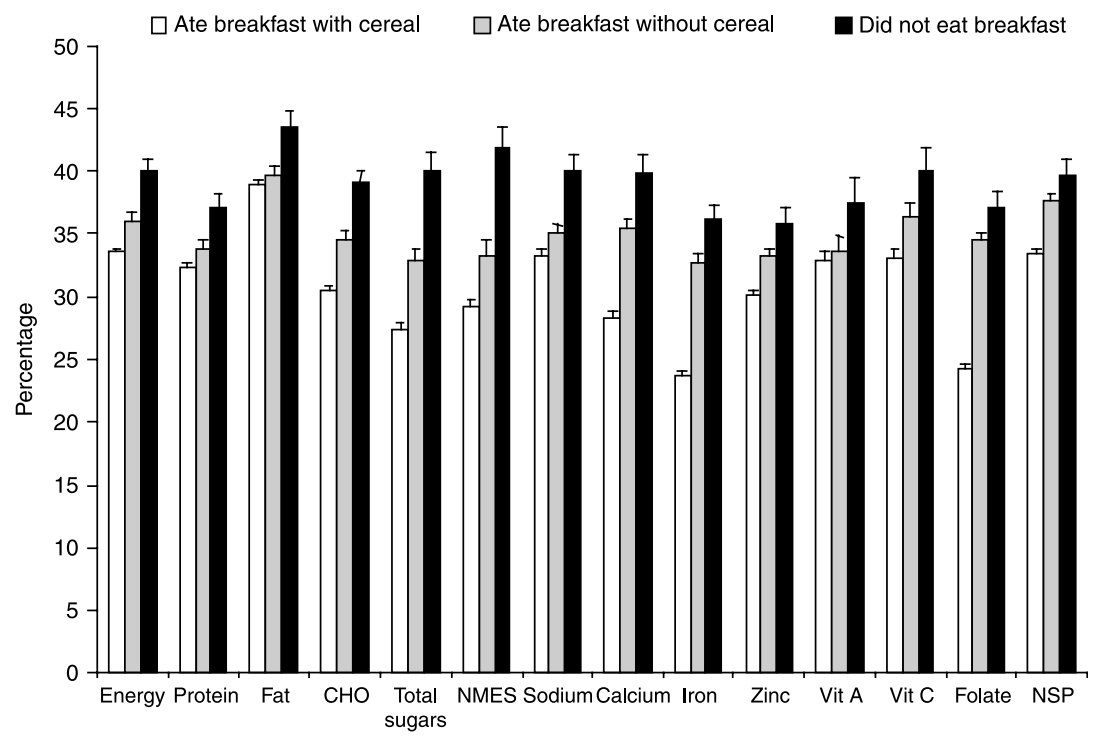

Fig. 6 Percentage contribution of school meals to total daily energy and nutrient intakes, according to whether the pupil had breakfast with cereal, breakfast without cereal, or no breakfast. Error bars show standard errors (CHO - carbohydrates; NMES - non-milk extrinsic sugars; NSP - non-starch polysaccharides) 
(a) Primary schools

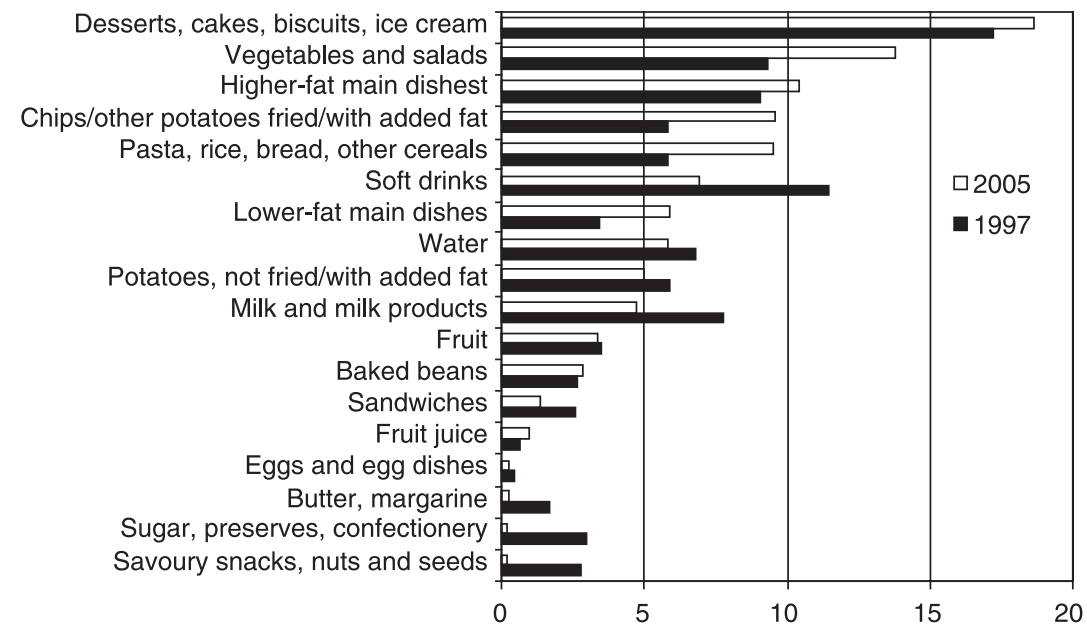

(b) Secondary schools

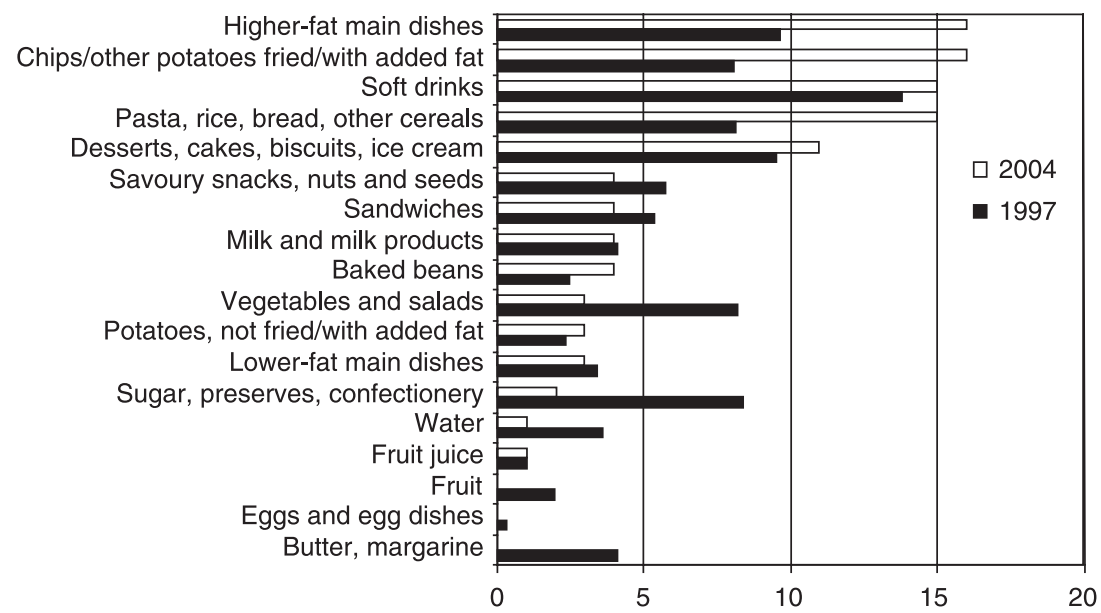

Fig. 7 Percentage of food choices amongst 1456 UK primary- and secondary-school pupils at school lunchtimes in 1997 compared with (a) those of 7058 pupils in 151 primary schools in England in 2005 and (b) those of 5695 pupils in 79 secondary schools in England in 2004

primary-school pupils, and low in zinc, calcium, iron, vitamin A and NSP in secondary-school pupils, especially girls. In addition, there were groups of young people whose diets were worse than average: those receiving free school meals, those from low-income families and those who do not consume breakfast, the majority in this group being teenage girls.

The evidence from the present analysis suggests that, if anything, school meals are making matters worse rather than better. The excess of foods high in fats and/or sugar and the deficits of cereal foods and fruits and vegetables, in comparison with the proportions recommended by the Balance of Good Health (Fig. 2), show that the choices that children are being allowed to make at lunchtime do not accord with what they have been learning in the classroom about balanced, healthy eating. This reflects a failure of the teaching process (i.e. pupils are not assimilating and putting into practice what they are learning about healthy eating) or suggests that pupils are being placed in an environment in which the choices on offer are, by and large, not consistent with the healthy eating messages that they have been learning. Evidence for the latter is provided in the recent reports on provision and consumption of school food at lunchtime in England ${ }^{6,7}$. When the pattern of food choices in school was compared with choices outside school (Table 2), it was evident that school food was typically worse than that provided outside school. The emphasis on desserts, higher-fat main dishes and chips and potatoes cooked with fat, and the failure to promote consumption of lower-fat main dishes, cereal products, milk and milk products, and fruits and vegetables, yields a pattern of consumption not consistent with the Balance of Good Health. The deviation of school food from the Balance of Good Health is so great, in fact, that it is unlikely that choices of food outside school could compensate for the imbalance created by school food. The national shortfall in fruit and vegetable consumption is not being redressed through school meals. 


\section{The most vulnerable}

Three groups of pupils (those living in households in receipt of benefits, those in receipt of free school meals and those not having breakfast) have been shown in the 1997 NDNS to have the poorest patterns of food consumption and mean nutrient intakes. For these groups, the presence of school meals is a benefit, in spite of the poor average quality of what is available. Pupils in receipt of free school meals, for example, derive a significantly higher average proportion of their energy and nutrient intakes from school meals (with the exception of vitamin A in secondary schools) than other pupils (Table 4). Thus, school meals clearly provide a safety net for the most vulnerable pupils. The fact that less than three-quarters of eligible pupils in the NDNS took up their entitlement (Table 3), slightly less than reported in the most recent surveys (79\% in secondary schools in $2004^{6}$ and $85 \%$ in primary schools in $2005^{7}$ ), gives cause for concern. Avoiding stigma through the use of smart card systems would probably be associated with an increased uptake of free school meals, ensuring further benefits for the most vulnerable.

For pupils living in families in receipt of Family Credit, no entitlement to free school meals formally exists. Responses of parents to questions of eligibility and the recording by interviewers of the consumption of free school meals by pupils (Table 3), however, suggest some discrepancies in the data. These may have arisen in part due to the movement of earners in the household into work following a period of unemployment (during which they would have been eligible for free school meals, but eligibility is likely to be assessed only once at the beginning of each school term) or to the failure of families to report changes in employment and benefit status. What is clear, however, is that the pupils from families in receipt of Family Credit also derive significant nutritional support from school meals, less than pupils receiving free school meals but typically greater than pupils in families not in receipt of any benefits (Fig. 5). Given this level of need, it would be prudent to reinstate eligibility to free school meals (removed in 1988 for pupils in families receiving Family Credit) for those pupils now living in families in receipt of Working Family Tax Credit or Child Credit, as a way of further promoting nutritional health amongst pupils from poorer backgrounds.

Pupils who do not eat breakfast have the worst diets on average, and school meals provide an even greater safety net than for pupils from the poorest backgrounds (Fig. 6). Measures to improve school meals (and, indeed, to provide healthy breakfasts at school) would be likely to have the greatest impact on this most vulnerable group.

\section{Changes in school meal consumption patterns}

Comparisons between the 1997 survey and the surveys conducted in 2004 and 2005 yield two conclusions. First, the profiles of food choices of pupils at school at lunchtime appear, overall, to be worse now than 7 or 8 years ago
(Fig. 7a and 7b). There are some trends in a more healthy direction (e.g. more vegetables and salads, more pasta and other cereals, and fewer soft drinks being consumed in primary schools; more pasta and other cereals and fewer sweets and confectionery being consumed in secondary schools), but many of the changes are in a less healthy direction, especially the preponderance of higher-fat main dishes and chips and other potatoes cooked with fat or oil, and the lack of fruits and vegetables in secondary schools. Some areas where improvement would be particularly desirable (e.g. more fruit consumption) show no change.

Some of the apparent differences may be methodological in origin. Many children and parents, in reporting the children's school meal consumption in 1997, will have reported the school meal consumption retrospectively over the previous $24-48 \mathrm{~h}$ (rather than prospectively as required by the survey method). They may therefore have been tempted to portray their diets in a more 'healthy' light. Even if children were reporting their actual consumption honestly using the prospective diary, their choices may well have been influenced by their participation in the survey. In 2004 and 2005, these biases did not apply. Although pupils knew that the survey was being carried out in the school, they were selected (using a randomised sampling technique) only after they had made their food choices. They were, therefore, much less likely to have altered their choices as a result of participation in the survey. Moreover, the observations were made directly by the interviewer, so the potential bias in the self-reported data (whether prospective or retrospective) was absent. Thus, it is likely that the $2004 / 2005$ data provide a more truthful picture of what schoolchildren were actually choosing at lunchtime.

Second, the findings suggest that the introduction of new school meal guidelines in 2001 have had little effect in promoting more healthy eating amongst schoolchildren at lunchtime. Although the foods on offer met the National Nutritional Standards in most schools on most days, the majority of schools clearly failed to promote the healthy choices. When given the choice, (like many adults) youngsters choose less healthy options. This suggests that stricter standards need to be put in place for caterers, teachers, pupils and parents, as part of a 'whole school' approach, to ensure that schoolchildren in the UK eat more healthily. Such an approach as been made in Scotland by the 'Hungry For Success' campaign ${ }^{11}$, but it is too early to tell whether the new guidelines have resulted in the desired changes in food consumption and health outcomes in Scottish schoolchildren.

The overwhelming conclusion from the present study is that widening pupils' choice of foods at lunchtime has had a detrimental effect on overall diet. Current provision falls below the 2005 CWT guidelines (Figs 3 and 4) - more so in secondary schools, where the range of choice is greater and the constraints on choice are fewer than in primary schools. Improvements in the quality of school food and 
limiting the range of choice to healthier options are likely to be the only way forward to bring pupils' consumption to the levels recommended by CWT and that reflect the Balance of Good Health. In the study of secondary schools $^{6}$, for example, restricting the number of days on which chips or potatoes cooked with fat or oil were served was associated with the greater likelihood that pupils' choices would meet the CWT guidelines for percentage of energy from fat. Improvements will be needed not only in the nutritional quality of the lunch but also in the dining room, to make school meals a more attractive, social and enjoyable experience. More interaction will be needed between caterers, teachers, pupils, governors and parents if the transition to healthier school meals is to be successful.

\section{Acknowledgements}

Sources of funding: The work was funded through salaries paid by the authors' host institutions or companies. There was no additional funding.

Conflict of interest declaration: The paper is based in part on the work and deliberations of the Nutrition Group of the School Meals Review Panel published in the Appendix of Turning the Tables (reference 8). There were no commercial or professional conflicts of interest in the preparation of the paper.

Authorship responsibilities: The work was led by M.N., who prepared the final manuscript. K.L. prepared first draft, and V.H. carried out the majority of the numerical and statistical analyses of the data and prepared many of the tables. The members of the Nutrition Group of the School Meals Review Panel contributed throughout to the text and the discussions informing the structure and contents of the paper.

\section{References}

1 Gregory J, Lowe S, Bates CJ, Prentice A, Jackson LV. National Diet and Nutrition Survey: Young People aged 4-18 years. London: The Stationery Office, 2000.

2 The Caroline Walker Trust. Nutritional Guidelines for School Meals. Report of an Expert Working Group. London: The Caroline Walker Trust, 1992.

3 Department of Health. Dietary Reference Values for Food Energy and Nutrients for the United Kingdom. Report on Health and Social Subjects No. 41. London: HMSO, 1991.

4 Parliamentary Office of Science and Technology. Childhood obesity. Postnote, September 2003, No. 205 [online]. Available at http://www.parliament.uk/post/pn205.pdf. Accessed 10 December 2006.

5 Department for Education and Skills (DfES). Guidance to caterers for school lunch standards [online]. London: DfES, 2001. Available at http://www.dfes.gov.uk/schoollunches/ default.shtml. Accessed 10 December 2006.

6 Nelson M, Badbury J, Poulter J, Mcgee A, Mseble S, Jarvis L. School Meals in Secondary Schools in England [online]. London: Department for Education and Skills, 2004. Available at http://www.dfes.gov.uk/research/data/ uploadfiles/RR557.pdf. Accessed 10 December 2006.

7 Nelson M, Nicholas J, Suleiman S, Davies O, Prior G, Hall L, et al. School Meals in Primary Schools in England [online]. London: Department for Education and Skills, 2006. Available at http://www.dfes.gov.uk/research/data/ uploadfiles/RR753.pdf. Accessed 10 December 2006.

8 School Meals Review Panel. Turning the Tables Transforming School Meals. Consultation Paper. London: Department for Education and Skills, 2005.

9 Crawley H. Eating Well at School. Nutritional and Practical Guidelines. London: Caroline Walker Trust, 2005.

10 Food Standards Agency (FSA). Eat Smart activity session 2: The Balance of Good Health [online]. London: FSA, 2004. Available at http://www.food.gov.uk/healthiereating/ nutritionschools/teachingtools/eatsmartplaysmart/eatsmart lessonplans/eatsmartlesson2. Accessed 10 December 2006.

11 Scottish Executive. Hungry for Success - A Whole School Approach to School Meals in Scotland. Final Report of the Expert Panel on School Meals. Edinburgh: The Stationery Office, November 2002. 